\title{
Cognitive Behavior Therapy
}

National Cancer Institute

\section{Source}

National Cancer Institute. Cognitive Behavior Therapy. NCI Thesaurus. Code C64345.

A type of psychotherapy utilized to treat different forms of mental disorders. The treatment involves the identification of unhelpful or destructive patterns of thinking and behaviors and the subsequent replacement with behaviors that are beneficial and constructive. 